\title{
Modeling and Simulation of the drive system of elevator based on AMESIM
}

\author{
Yingjie Liu ${ }^{1,2, a^{*}}$, Hejun $\mathrm{Yu}^{1,3, b}$, Gang $\mathrm{Li}^{1, \mathrm{c}}$, Zhongxing $\mathrm{Li}^{1, \mathrm{~d}}$, Xingjun $\mathrm{Wu}{ }^{1, \mathrm{e}}$ \\ ${ }^{1}$ Guangzhou Special Electromechanical Equipment Inspection Technology Institute, Guangdong \\ Guangzhou 510180 \\ ${ }^{2}$ Zhejiang University, Zhejiang Hangzhou 310027 \\ ${ }^{3}$ South China University of Technology, Guangdong Guangzhou 510641 \\ a*Yingjieljd@163.com, ${ }^{b} 578912667 @ q q . c o m,{ }^{c} 616960080 @ q q . c o m,{ }^{d} 285669644 @ q q . c o m,{ }^{e}$ Wuxingj \\ un@163.com
}

Keywords: elevator; AMESIM; drive system; modeling; simulation.

Abstract. The drive system of an elevator controls the starting and accelerating, smooth running and braking deceleration of the elevator. The quality of elevator's performance is closely related to the design of the drive system. This paper carries on the modeling and simulation of elevator's drive system by using AMESIM software, and analyzed the control performance of the system under different condition such as the different load, control parameters wire rope stiffness and traction wheel rotation inertia effect. It provides a simple and effective method for simulation and test of the dynamic performance of the elevator's drive system with different control parameters.

\section{Introduction}

The elevator is an important high-rise building transport vehicle. The drive system of an elevator controls the starting and accelerating, smooth running and braking deceleration of the elevator. The quality of elevator's performance is closely related to the design of the drive system. A high quality elevator need to be safe, comfortable, fast, with small vibration as well as high leveling accuracy ${ }^{[1]}$.

Currently in the old-fashioned elevator drive system, the drive mode mainly include: AC double-speed drive systems, AC variable voltage control system, VVVF system ${ }^{[2]}$. Before 1995, almost all high torque, low speed, precise operation and motor control, high precision leveling traction elevator used DC motor to drive. In the late $1990 \mathrm{~s}$, Japan's Mitsubishi Electric Corporation developed the first variable frequency variable voltage (VVVF) speed control elevator. KONE Company developed a called Eco Disc gearless permanent magnet synchronous machine in 1996, the first Machine roomless elevator (MRL) was born. MRL is the past ten years the most significant Elevator Industry Innovation ${ }^{[3]}$. At present, the MATLAB software is mainly used in the modeling and Simulation of the elevator drive system of which the model of each subsystem needs to be built and programmed. AMESIM is a collection of mechanical, electromagnetic, control, hydraulic, pneumatic and other integrated simulation software which was developed by LMS imagines Company. Use it to build drive model of traction system, can enhance the efficiency of building the model for elevator drive system greatly, while in the latter parameter testing is also convenient. This paper based on the analysis of mathematical model of variable frequency traction machine controller, using AMESIM software to build the model of the traction machine control part and drive mechanical part. Finally build the model of the whole traction machine drive system. Simulation analyses of the model and simulation results are given. Alter the physical parameters and control parameters based on the model and control performance of traction machine can be obtained. Seen from the simulation results, the control system can run smoothly, and has good control characteristics, it saves the developing time for new control system for elevator. 


\section{Mathematical model of the elevator drive system}

The basic structure of the drive system of elevator. Elevator drive system includes traction system, electric drive system and electric control system. This paper mainly discusses the modeling and Simulation of traction system and electric drive system.

Mathematical model of traction machine frequency conversion controller. In order to facilitate analysis, assuming a) Magnetic circuit is not saturated, that is, the size of the motor inductance is not affected by the change of the current, regardless of the eddy current and hysteresis loss; b) ignoring the effect of cogging, commutation process and armature reaction; c) three-phase winding is completely symmetrical, the permanent magnet magnetic field along the air gap around the sinusoidal distribution; d) armature windings in the stator surface is uniformly continuous distribution; e) drive diode and freewheeling diode is ideal components. The mathematical model of the system is shown in the following formula (1).

$$
\left.\begin{array}{c}
u_{d}=r i_{d}+L_{d} \frac{d i_{d}}{d t}-\rho \omega L_{q} i_{q} \\
u_{q}=r i_{q}+L_{q} \frac{d i_{q}}{d t}-\rho \omega\left(L_{d} i_{d}+K_{e}\right) \\
J \frac{d \omega}{d t}+B \omega+T_{l}=T_{e} \\
T_{e}=\frac{3}{2} p K_{e} i_{q}
\end{array}\right\} .
$$

$r-$ each phase winding resistance, $L-$ each phase winding inductance, $\omega-$ Mechanical angular velocity, $K_{e}-$ BEMF coefficient, $J-$ Moment of inertia, $B-$ Viscous friction coefficient, $T_{l} \longrightarrow$ Load torque, $p \longrightarrow$ Motor pole pairs.

\section{AMESIM simulation model}

AMESIM software. AMESIM is a collection of mechanical, electromagnetic, control, hydraulic, pneumatic and other integrated simulation software. Use it to build drive model of traction system, can greatly improve the speed to build the system. It has a plurality of sub-modules can be easily operated such as machines, control, motor and others.

The establishment of an elevator's drive system model. According to the characteristics and mathematical model of traction machine drive system, using AMESIM software to establish model of control system of variable frequency traction machine controller and traction machine. Then establish the elevator's drive system model as shown in Fig.1. 


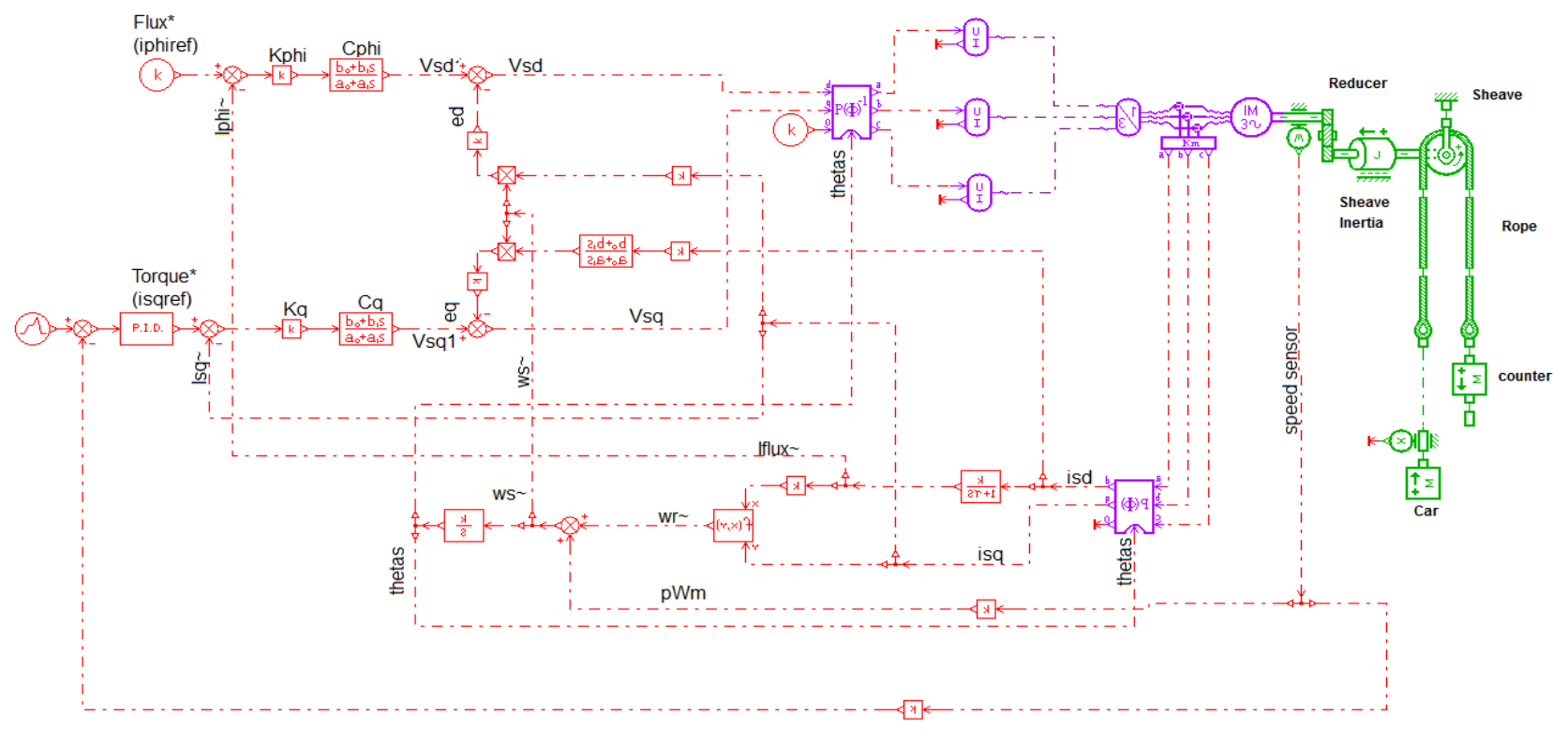

Fig.1. elevator's drive system model

The simulation parameters are as follows. Induction motor pole number is 2 , dispersion coefficient is 0.066 , stator inductance is $0.25 \mathrm{H}$, stator reactance is $10 \mathrm{ohm}$, rotor time constant is $0.153 \mathrm{~s}$, initial value of moment of inertia is $20 \mathrm{kgm}^{2}$, viscous friction coefficient is 0.5 , traction sheave diameter is $500 \mathrm{~mm}$, rope rigidity per meter is $1 \mathrm{e}+009 \mathrm{~N} / \mathrm{m}$, viscous friction is $100 \mathrm{~N} / \mathrm{m} / \mathrm{s}$, initial length is $40 \mathrm{~m}$, car weight is $800 \mathrm{~kg}$, heavy weight is $1000 \mathrm{~kg}$, PID module control parameters are: Proportional parameter $\mathrm{P}=40$, Integral parameter $\mathrm{I}=1$, Differential parameter $\mathrm{D}=0$.

The simulation results are shown in Fig 2 to 5, as can be seen from the speed response curve, the speed at start soon after reaching a stable value, less volatile. In the torque response curve, the initial value after the electromagnetic torque fluctuations stabilized at $0 \mathrm{Nm}$. Slight fluctuations occur in the acceleration and deceleration of the lift, during operation is maintained at $0.5 \mathrm{Nm}$.
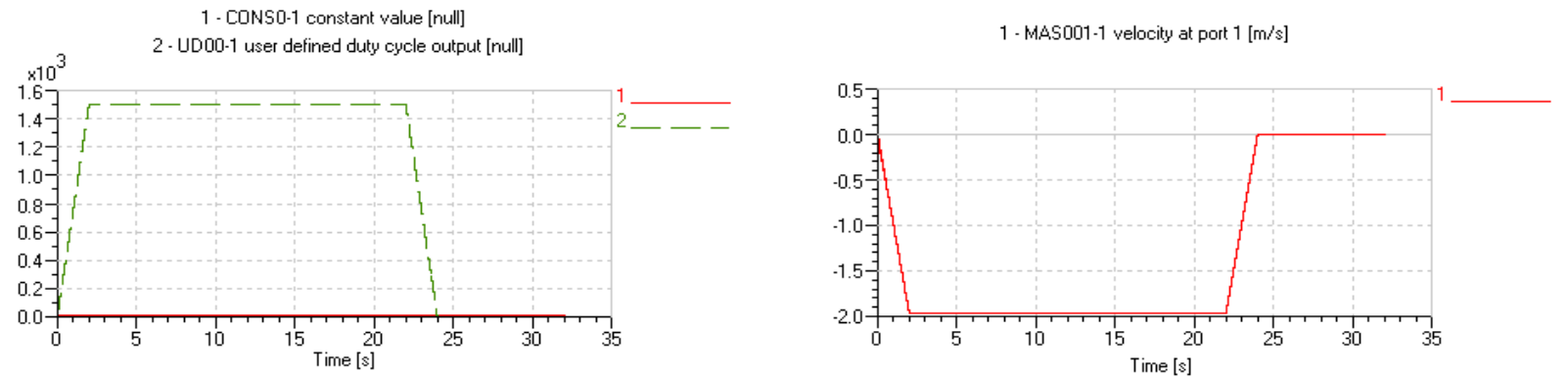

Fig.2. Given speed and excitation current control curve

Fig.3. Car speed curve
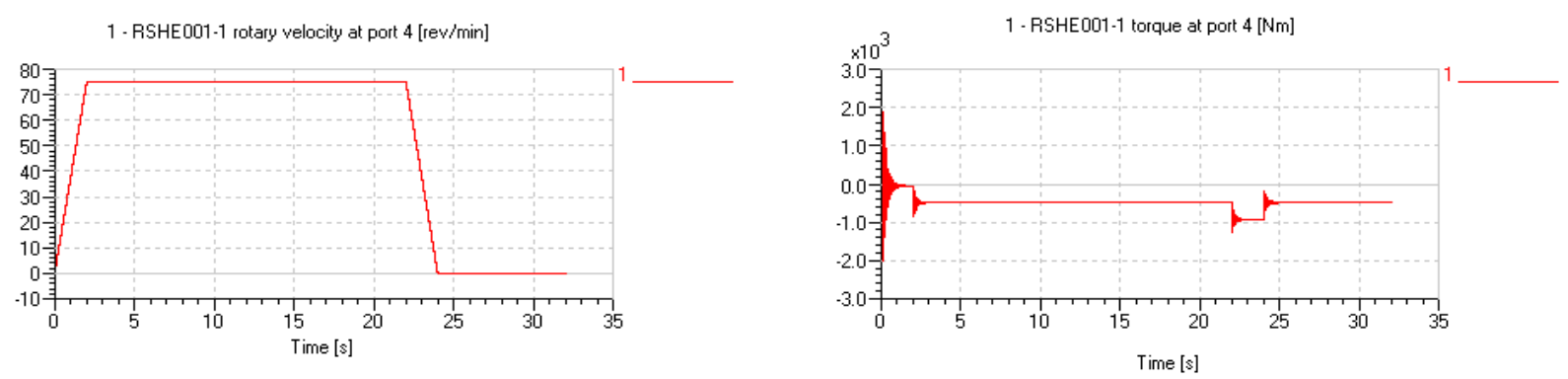

Fig.4. Sheave rotation angular velocity curve

Fig.5. Sheave moment diagrams 


\section{Simulation and Analysis}

Load impact on the speed control. The load increased gradually from $700 \mathrm{~kg}$ to $1300 \mathrm{~kg}$, and the change range was $75 \mathrm{~kg}$. The speed control curve is shown in Fig.6. From Fig. 7 can be seen with the increase of the load, the speed of a slight fluctuation, but the final stability to a given speed.

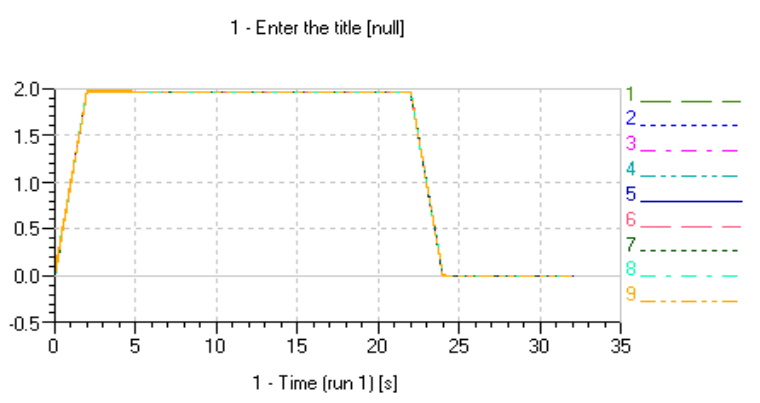

Fig.6. Speed control curve

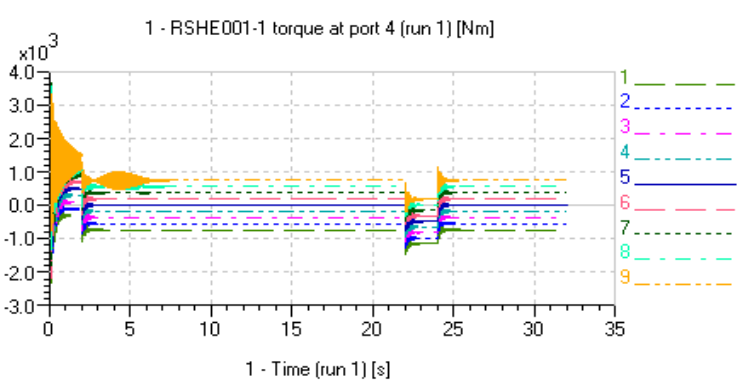

Fig.7 Torque curve

Effect of different control parameters on the control accuracy of the car. Setting proportional parameter of the PID module as $0.1,1,10,100$ (curve1, 2, 3, 4 respectively), the other parameters constant. Car weight is $800 \mathrm{Kg}$, heavy weight is $1000 \mathrm{Kg}, \mathrm{KI}=1$. The control curve shown in Fig. 8 to 9. With different parameters, the velocity curve has a slight fluctuation. The selection of proportion parameter has large effect on the stability of the speed.

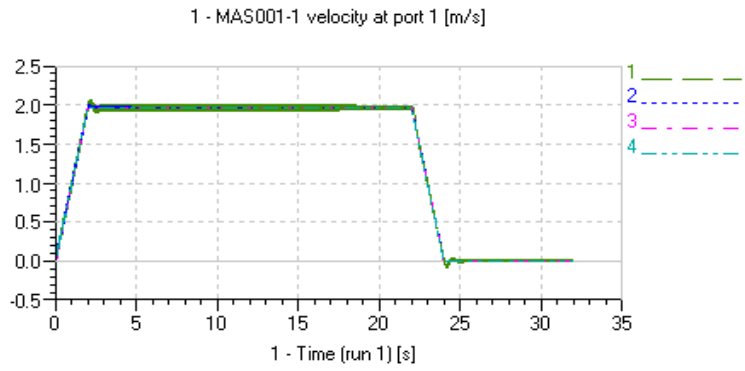

Fig. 8. Speed curve

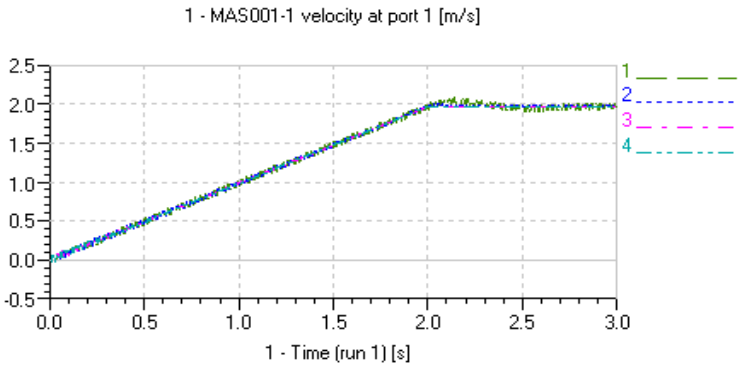

Fig.9. Speed curve

Effect of rope rigidity on control effect. The stiffness of the rope are set at $1 \times 10^{-7}, 1 \times 10^{-8}, 1 \times$ $10^{-9}, 2 \times 10^{-9}$ (corresponding to curve 1,2,3,4), From Fig.10to11, the influence of wire rope stiffness on control effect is obvious. With different stiffness control curve fluctuates greatly. When the stiffness value is $2 \times 10^{-9}$, the control effect is ideal.

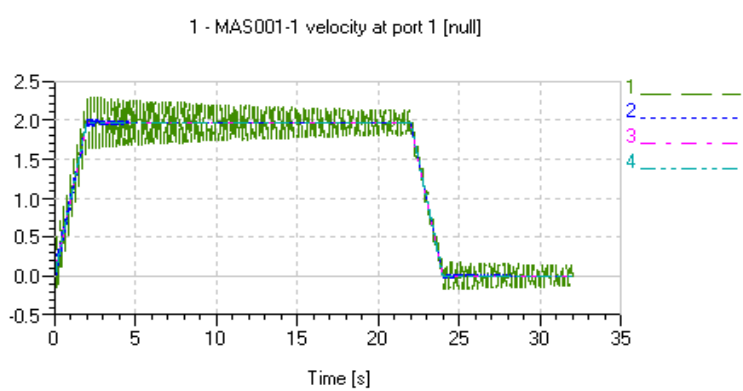

Fig.10. Speed curve

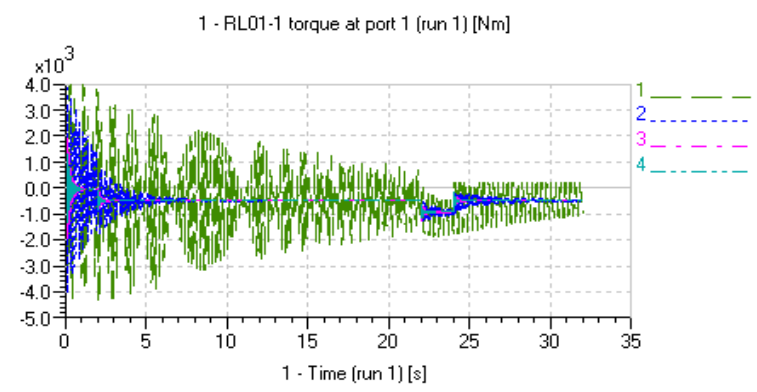

Fig.11. Torque curve

Different sheave rotational inertia influence on control effect. Set a different moment of inertia traction sheave, which controls results is shown in Fig. 12 to 13. 


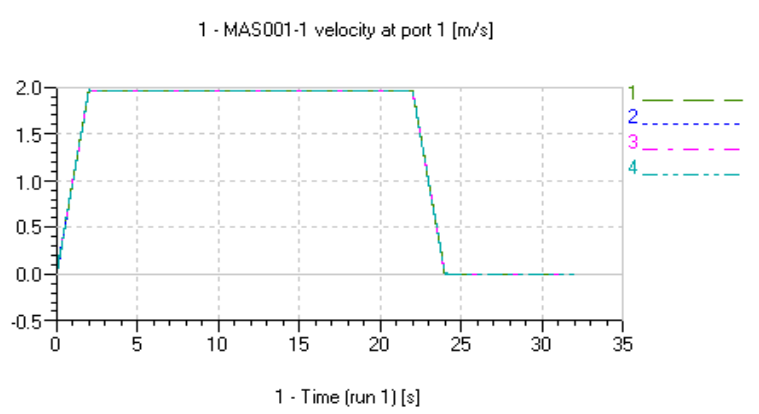

Fig.12. Speed control results

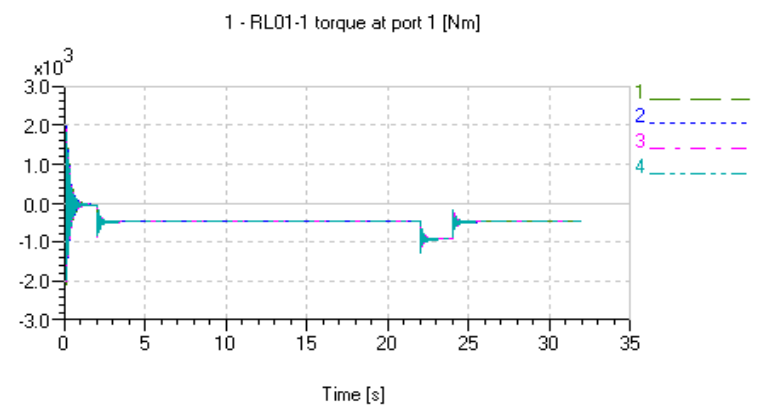

Fig.13. Changes torque curve

\section{Conclusion}

This paper based on the analysis of mathematical model of variable frequency traction machine controller, using AMESIM software to build the model of the whole traction machine drive system. Seen from the simulation results, the system can run smoothly, and has good control characteristics. When changing the lift load or PID proportional parameter, control speed appeared slight fluctuations, when changing the rope rigidity, control speed along a given speed appeared more substantial fluctuations. It provides a simple and effective method for simulation and test of the dynamic performance of the elevator's drive system in different control parameters.

\section{Acknowledgment}

This work is supported by Guangdong Province Science and Technology project (No.2014A040401046), and Guangdong Quality and Technique Bureau Science and Technology project (2015PT01).

\section{References}

[1] Guiming Du, Liqin Pang, Present situation and development prospect of the control technology of the elevator drive system, J. China New Technologies and Products, 2010 (09) 17.

[2] Xue Wang, Domestic and international development trends of elevator drive technology, J. Guide of Sci-tech Magazine, 2014 (12) 147.

[3] Zhiqun Luo, Xiaoxiong Zhuang, The latest development trend and application of the elevator drive technology, J. Construction machinery technology and management, 2003 (10) 74-76.

[4] Ping Yang, Ruiqing Ma, Yun'an Zhang Modeling and simulation method of PMSM control system based on Matlab, J. Journal of Shenyang University of Technology, 2005, 27(2) 195-199.

[5] Yunfei Gong, Lixing Fu, Simulation Research on vector control system of PMSM based on Matlab, J. Micro motor, 2007, 40 (2) 33-36.

[6] Yongling Fu, Haitao Qi, LMS Imagine Lab AMESIM System modeling and simulation tutorial examples, Beihang University press, Beijing, 2011.

[7] Suhua Wang, New type of elevator traction machine drive and control system design and Implementation, Master degree thesis of Nanjing University of Science and Technology, Nanjing, 2013.

[8] Xiaofeng Wan, Lan Liu, LMS Virtual Lab Motion Introduction and improvement, Northwestern polytechnic university press, Shanxi, 2010. 